McKenzie's Stages II, III and IV these would be progressively transferred to others, either on board or ashore, generating additional expenditure.

(c) Two watchkeepers would have sufficient capacity to carry out additional duties, such as the monitoring of engine conditions where the engine room is unmanned, further contributing to the reduction of overall costs.

The case for removing the rating from the bridge is not argued as it must be clear that for navigational functions he is not cost-effective. Any tasks which an officer might not reasonably be expected to undertake would be dealt with by day work ratings, working overtime as necessary.

The introduction of all-officer bridge manning on this scale might be quite difficult, and it may not be the optimum solution, but it would seem worthy of careful consideration and costing before embarking on the alternative course towards an all-electronic ship.

\title{
Some Thoughts on Marine Radar
}

\section{Gregory Haines}

I. The man/machine interface. People who design motor cars also drive them, but whoever heard of a radar design engineer who also had a Master's ticket ? Of course, the designers of marine instruments do go to sea occasionally, but not for longer than they can help; sea-time is apt to interfere with the weekend. So it happens that the people who make marine radars are rather remote from those who use them, and from the environment in which they work, the sea. The engineer might argue that no two seamen ever seem able to agree on what they want, so the easiest thing is to decide for them, and that, in any case, it is only a matter of ergonomics. On the other hand, it may be that the people who write books on ergonomics have not been to sea either. Radars are used in the dark, as are motor cars, but the darkness of the bridge is not the same as night driving. The identification of controls in the pitch black night by position, shape or edge illumination; the best kind of lighting for the legends, and their grouping according to importance, are all matters that never seem to receive the attention they deserve. The calm of the middle watch is suddenly shattered by flashing light and strident buzzer and the hapless watchkeeper gropes for a torch to find out what it means. The function of a radar in its simplest terms is to measure the ranges and bearings of other ships, so the method of obtaining and recording this information would seem to be of the first importance, yet in the design of many radars it is treated as an after-thought. I have even seen a display that was apparently designed for operators with two left hands, since the controls for the bearing ring and range strobe were both on the same side of the PPI display. For my money these two most important operating controls should be of the spinning, dynamically loaded, type. To combine rapid traversing and fine adjustment, two-speed gearing is necessary. (Whatever happened to the main tuning dial of this type that was always used in the wireless sets of an earlier age ?) The range and bearing read-outs should be in large digits with an illumination adjustment that is 
continuous and separately controlled. Ideally, the range strobe should be continuously visible, on demand, not flashed up each time the scanner passes the bearing. One could go on with such obvious points indefinitely-obvious enough but seldom met by radars on the market today. At this point the designers are apt to shake their heads and start muttering about costs, but the fact is that electronics men are usually more interested in logarithmic wizardry than the user's problems. Radars, in a word, are for the most part designed from the inside out, rather than from the outside in.

2. The anti-COllision problem. Volumes have already been written and much ingenuity expended on the ideal display. Starting from first principles, this should surely be one that reflects as closely as possible reality, as seen from the bridge of a ship. This is a ship's head-up display showing the true motion of other ships and with own ship always at the centre of the tube. This can be done with a non-persistent tube, either by storing past history and displaying it, appropriately offset, in conjunction with the present picture, or by computing the velocity vectors of all, or selected, targets from successive echo information and displaying the result on a separate tube. Iotron, Cerci, AEI, Noratom and Sperry have produced vector displays and Kelvin Hughes, Marconi Raytheon and Decca, in a limited way, offer history in 'some sort. Of these, Iotron, AEI, Marconi and Noratom show the ship at the centre. But all these manufacturers, and there may be others, have developed secondary displays, not so much with the idea of achieving the ideal presentation as such, as of making a step towards the solution of the anti-collision problem. Perhaps they have been stung by the allusion to 'radar-assisted collisions' or are facing the necessity to come out with a new thing. Whatever the reasons for them, all these attempts to solve the anticollision problem, always bristling with unique features, are unlikely to make much difference to the collision statistics in the immediate future. The problem is pretty well insoluble within the inevitably narrow terms of reference of the radar engineer. For one thing, all the calculations of closest approach and all assessments of the risk depend on the assumption that the other ship, or ships, will continue on their present courses and speeds whereas it is precisely the late and possibly ill-considered alteration that is almost invariably the last fatal link in the chain of events leading to an accident. In an attempt to alert the unwary, manufacturers provide all sorts of alarms when ships come within certain ranges or are predicted to be coming too close some time in the future. Entering. the Dover Strait on a busy day the noise must be almost continuous, until the Officer of the Watch switches off the whole system in exasperation. Yet the only alarm which would be really worth having, and which could easily be provided with a vector display system, is provided by no-one. That would be an immediate warning of an alteration of course by any marked ship within a specified range. The missing link is a ship-to-ship identification and communication system, but that is outside the radar designer's province at the present time. In one sense, of course, the whole problem is self-defeating. As improvements are made-and the introduction of marine radar was a very notable one-ships tend to travel faster, in thick weather for example, until the degree of risk as it previously existed is again approached. So it is with the motorways. Better roads do not much reduce collisions, but make them more serious when they do occur; an application of the gloomy theory of Malthus. However, on a less defeatist note, it is obvious that the accident rate can be controlled and reduced. One only has to suppose that every collision resulted in virtually certain loss of life to all concerned, as 
it does in the air. In such circumstances there would be no collisions. Ships would proceed with much more caution than they do now and they would certainly be controlled from shore in all congested areas. Possibly therefore, if I may dare to say so, radar designers would do better to think of ergonomics, the ideal display and absolute reliability than to lavish their talents on complex anti-collision systems that will always seem more effective in the classroom than on the sea. Finally, there is an evident need for more radar softwear. Radar training afloat would be a great deal more effective than it can ever be ashore and supertankers are large enough to accommodate a school.

\section{Radar at Sea}

\section{H. L. Lubin}

As one of the authors of Marine Radar and How to Use It which was reviewed by Captain Cockcroft in the October 1971 issue of this Journal I feel it necessary to reply to some of his comments. Though he and I may disagree on a few points the authors can only be pleased to have had someone so well known take the time and effort to review our book.

In discussing radar interference he quotes our comment that it is comforting to know that a radar-equipped ship has the equipment operating, and adds 'Unfortunately this cannot be relied upon as the interference may be caused by a vessel at greater range.' But we went on to say '. . . with a radar set that is operating and hopefully being intelligently used'. How far away the other ship is wasn't the point at all. The objective was to indicate that one will see radar interference on his own scope now and then and that is not to be relied upon as an indication of some sort of intelligent analysis at its source.

Paragraph four of the review is a bit misleading in itself. We do recommend gyro-stabilized relative motion plotting and the use of the reflection plotter. The problem exercises were certainly presented as manœuvring board solutions as we could see no other way to indicate the solution procedures in the book. But '. . . plotted at the centre' was only part of the instruction material, and to get the reader through the basics to the 'off centre' method proposed to be used on the reflection plotter in real life.

The real cause for comment is based on the review from paragraph five onwards. Though the book was basically a joint effort, the collision avoidance chapter was my own and the comments to follow are mine.

The Rules have, no doubt, been memorized by every seafarer who has been one for any length of time. Even in his cups, he will be able to quote any rule you ask for verbatim. When it comes to acting on these rules, however, the difference between how clear they are and how precise they are begins to take its toll. Whether we are privileged or burdened, i.e. we can see each other (and what if only one of us sees the other ?), or whether we have been radar-watching each other, begins under the Rules to complicate the sailor's life. Whether Rule 21 or $16(\mathrm{c})$ applied is (pardon the heresy) begging the point. The vital object of any of the Rules-is to prevent a collision and further, in my opinion, to preclude even the risk of one. 